\title{
Randomized Clinical Trial Comparing Dialogical Family Guidance with Ordinary Clinical Treatment for Families with a Child with Neurodevelopmental Disorders
}

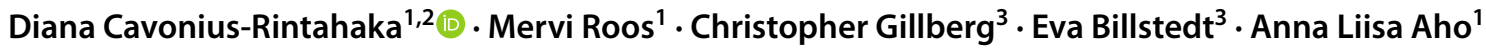

Accepted: 23 November 2021 / Published online: 8 December 2021

(c) The Author(s) 2021

\begin{abstract}
Objectives Previous studies have highlighted the need to offer targeted interventions to strengthen the wellbeing of family members in families with children with neurodevelopmental disorders (NDD). Interventions for this target group require research and development. The purpose of this study was to test a new family intervention: Dialogical Family Guidance (DFG).

Methods Families of children with NDD were randomized into an intervention group that was delivered DFG and a comparison group provided with ordinary clinical treatment. The Family Functioning, Family Health and Social Support (FAFHES) and the DFG instrument were used to collect data at baseline and after 3 months. Repeated measure analysis of variance (ANOVA) was used as an analytical strategy.

Results There was a significant within-subjects effect of time on family health and social support, indicating that family health and social support increased in both groups over time. There was also a significant between-subjects effect of group and interaction between time and group on social support, indicating that social support increased more in the intervention group than in the control group. Managing in daily life and the relationship between parents were associated with family functioning and family health.

Conclusion DFG can strengthen parental experiences of social support. Managing in daily life, relationship between parents, practical guidance, psychoeducation, dialogue, and receiving positive feedback on parenting were strengthening factors during DFG. However, the results of this study must be considered as only preliminary, as they relate only to parental perceptions of the intervention effects.
\end{abstract}

Trial registration ClinicalTrials.gov NCT04892992 (retrospectively registered).

Keywords Dialogical Family Guidance $\cdot$ Family functioning $\cdot$ Family health $\cdot$ Social support $\cdot$ Neurodevelopmental disorders $\cdot$ Effects

Neurodevelopmental disorders (NDD) are a group of disorders with an onset in the developmental period of childhood.

Diana Cavonius-Rintahaka

diana.cavonius@gmail.com

1 Faculty of Social Science, Nursing Science, University of Tampere, Tampere, Finland

2 Child Psychiatry, Neuropsychiatric Unit, Helsinki University Hospital (HUH), Ratapihantie 11, 00520 Helsinki, Finland

3 Gillberg Neuropsychiatry Centre, Institute of Neuroscience and Physiology, Sahlgrenska Academy, University of Gothenburg, Gothenburg, Sweden
NDD is a general term used to describe neurological and psychiatric disorders such as learning and language disorders, intellectual disabilities, motor coordination disorders, autism spectrum disorders (ASD), attention deficit hyperactivity disorder (ADHD), tic disorders, and oppositional defiant disorder (ODD). NDDs are characterized by high rates of impairment or comorbidities between various disorders within this diagnostic grouping (Morris-Rosendahl $\&$ Crocq, 2020). ADHD and ASD are both highly heritable and impairing NDDs but can also be triggered by pre- and postnatal risk factors. Smoking during pregnancy, prenatal exposure to alcohol, young maternal age, and maternal stress increase the risk for ADHD in children (Oerlemans 
et al., 2016). According to Faraone et al. (2015), ADHD is a persistent neurodevelopmental disorder that affects $5 \%$ of children and adolescents and $2.5 \%$ of adults worldwide, and involves a risk of psychiatric disorders, educational and occupational failure, accidents, criminality, social disability, and addictions. A study by Simonoff et al. (2008) revealed that $70 \%$ of children with ASD had at least one comorbid disorder, and $41 \%$ had two or more comorbidities. Moreover, Lai et al. (2014) reported that ASD affects more males than females and that over $70 \%$ have comorbidities. Common comorbidities in NDD include ODD symptoms, aggression, language disorder, anxiety disorder, and sensory integration disorder. Soke et al. (2018) compared the prevalence of cooccurring symptoms between 4-year-old and 8-year-old children with ASD in a large population-based group. Over 95\% of the 8-year-olds had at least one co-occurring symptom while this was the case with $67 \%$ of the 4 -year-olds, as some conditions may have not yet been identified at that age. The findings obtained in this study are informative and therefore useful for professionals when developing interventions and services for this target group.

The symptoms and profile of NDD development may also change during childhood, and these multiple NDD symptoms are presented by Gillberg (2010) in the concept of ESSENCE (Early Symptomatic Syndromes Eliciting Neurodevelopmental Clinical Examinations). ESSENCE refers to children presenting impairing symptoms before the age of 3 (to 5) years in clinical settings in the domains of general development, communication and language, social inter-relatedness, motor coordination, attention, activity, behavior, mood, and/or sleep. According to Gillberg (2010), major problems in at least one ESSENCE domain before the age of 5 should be paid attention to as (very likely) markers for the presence of a neurodevelopmental disorder, and which can indicate later, continuing problems. Children who screen positive for ASD have considerable and clinically relevant impairments and psychiatric problems, and their impairment is often mainly caused by their comorbidities. In a population-based study by Posserud et al. (2018), only $2 \%$ of children could be characterized as having "autism only," and they recommend comprehensive clinical assessments that include neurodevelopmental, psychiatric, and cognitive assessments and follow-up meetings, regardless of the final clinical diagnosis. This study supports taking an ESSENCEbased approach, as there is very high overlap across a wide range of symptom domains.

Having a child with NDD often means that other members in the family (parent or siblings) are also likely to have NDD symptoms due to strong genetic influences (Biederman, 2006). According to findings from twin, family, and adoption studies, the heritability of ADHD is estimated to be at 70-80\% (Biederman \& Faraone, 2005; Hudziak et al., 2005; Thapar et al., 2000). Similarly, Faraone and Larsson (2019) have referred to decades of research showing strong heritability in the etiology of ADHD. As a result of the high heritability rate, it is possible that several parents have ADHD and their own symptoms can have an impact on their parenting skills (Tarver et al., 2014). According to Chen et al. (2017), ADHD for example manifests in parents or siblings of children with an ADHD diagnosis 2-8 times more frequently than seen in the general population. Genetics also affect the etiology of ASD, and the heritability is estimated to be between 64 and 91\% (Robert et al., 2017; Tick et al., 2016a, b). It is also known that both disorders co-occur with a frequency of $20-50 \%$ in children with ADHD meeting criteria for ASD, and 30-80\% of ASD children meeting criteria for ADHD (Rommelse et al., 2010). In their recent study, Okyar and Görker (2020) argue that autistic traits are frequently detected in children with ADHD. As expected, not only more symptoms of autism were detected in boys, but also the presence of ODD. According to this study, maternal and paternal ADHD symptoms predict autism symptoms in children with ADHD.

There is a need for interventions to improve health and functioning aimed at both parents and children. Parents of children with special needs demonstrate fatigue and exhaustion, and emotional problems ranging from frustration to hopelessness (Caicedo, 2014). We also know that parents of children with NDD such as ASD experience more stress than parents of typically developing children (Craig et al., 2016; Duarte et al., 2005; Johnston et al., 2012). Studies have revealed that there is a relationship between family functioning, quality of life and the typical characteristics of children with a range of NDD disabilities, and parental stress levels (Craig et al., 2016; Falk et al., 2014; Pisula \& Porebowicz-Dorsmann, 2017). Van Steijn et al. (2014) have reported that both parents of children with ADHD and ASD are at a risk of experiencing higher levels of stress. Paternal ASD and maternal ADHD symptoms have been related to increased stress, and these factors have been found to be associated with a higher incidence of depression. High levels of parenting stress may have negative effects on the entire family system and the individual's quality of life. Divorce rates remain higher in parents of children with autism compared to parents of normally developed children (Hartley \& Schultz, 2015; Hartley et al., 2010).

Providing parents with an opportunity to voice their concerns, communicate with other adults, or to get temporary relief from their role as caregivers can prove to be effective interventions for reducing the stress that parents often 
experience. According to Seikkula and Trimble (2005), this is called reflective dialogue.

Families play an important role for children with NDD, and parents are often the first ones to recognize the child's symptoms. While the positive impact of families is wellknown, there is a need for more knowledge to understand how parents manage their child's ADHD in their everyday lives. It is also important for nurses working with children and families to recognize the effort and skills required from caregivers in managing their child's condition, and to introduce behavioral management strategies as early as possible, along with support, counseling, or psychosocial services (Paidipati et al., 2020).

It is also known that parents who also have ADHD have a weaker sense of coherence and poorer family functioning than parents without ADHD, and support from health services is strongly associated with a positive effect on family functioning (Moen et al., 2015). Adults with ADHD are known to have more depression, anxiety, greater childhood dissatisfaction, a more external locus of control, and lower self-esteem (Rucklidge et al., 2007). A less organized family environment can exacerbate impulsive and hyperactive child behavior to a more serious level, instead of facilitating selfregulation skills in the child. Shared genetic vulnerabilities combined with child difficulties and stress in families are an environmental risk for families. ADHD in parents appears to confer specific impairments in parental functioning in families of children with ADHD (Johnston et al., 2012). Parenting may also be a protective factor associated to functioning outcomes in children with ADHD as parents play a major role in their child's social environment. Parents who themselves have ADHD may benefit from targeted, more individualized parenting interventions that have an additional focus on the parents' planning and organizational skills (Johnston et al., 2012; Tarver et al., 2014).

Findings from studies have led to developing and proceeding with treatments and interventions and providing families with support. Several studies have addressed a need for nonpharmacological interventions to be more specially targeted towards NDD symptoms (Sonuga-Barke et al., 2013; Tarver et al., 2014). Individuals' functional independence and quality of life should be maximized throughout their development, and they should be helped in finding their areas of strength. According to Lai et al. (2014), the most effective interventions for ASD are behavioral and educational, but medication should also be considered, especially in persons with co-occurring symptoms. Similarly, Tarver et al., (2014, 2015) have reported that behavioral parenting interventions should be used as the first-line treatment of ADHD, although there is still a need for future trials of non-pharmacological interventions. Sonuga-Barke et al. (2013) also challenge future research to improve the efficacy of nonpharmacological interventions, while at the same time building a growing understanding of ADHD pathophysiology. Interventions should be better integrated with pharmacological approaches and focus on family-related functional outcomes. Parenting interventions can be perceived as a component of treatment targeting a wide range of outcomes and providing additional benefits, although they would not be effective in combating core ADHD symptoms (Tarver et al., 2014). Important targets for interventions include promoting the psychosocial wellbeing of parents and helping them to resolve the emotions associated with their child's diagnosis (Barlow et al., 2014; Wachtel \& Carter, 2008).

According to Craig et al. (2016) and Schwartzman et al. (2021), the parents of children with different types of NDDs should be provided with interventions that empower them with knowledge and skills to reduce their stress and improve their quality of life. Findings from these studies suggest that children's emotional and behavioral problems are significant sources of parental stress. There are several intervention models targeted on specific symptoms of ASD (Bearss et al., 2015; Factor et al., 2019; Farmer \& Reupert, 2013) or ADHD (Sonuga-Barke et al., 2013; Trillingsgaard et al., 2014). New findings demonstrate for example resiliencebased interventions for parents with children with ASD (Schwartzman et al., 2021) and mindfulness-based interventions for parents with children with ADHD (Siebelink et al., 2021) as promising. A review by Barlow et al. (2014) revealed short-term evidence of the benefits of parenting programs on depression, anxiety, stress, anger, guilt, confidence, and satisfaction with the partner relationships. Other studies (Barlow et al., 2014; Dretzke et al., 2009; Michelson et al., 2013) have also reported that caregiver training and interventions have a general impact on family functioning and interpersonal relationships within the family. This suggests that parent and family involvement and the inclusion of family members in interventions would probably result in a greater effectivity and impact of treatments for the entire family (Ansari et al., 2016; Lai et al., 2014). This is in line with the findings of Rodriguez et al. (2019), which suggest that family-based interventions aimed at both parents and children with ASD bring understanding to the reciprocal link between parental stress and child functioning. Such interventions could include providing parents with training on how to cope with stress, and how to respond to demanding child behavior in a beneficial way.

Strictly manualized psychoeducational programs do not necessarily make room and/or give time for family members to express their dilemmas and questions, although it is well known that having a child with NDD can have various, and at times even serious impacts on different family 
members. Dialogical Family Guidance (DFG) was developed as a family intervention with the purpose of helping all family members to receive psychoeducation and increase their understanding of NDD/ESSENCE. DFG has been tailored for families with a child with NDD and aims to meet uniqueness of these families by using dialogue and the knowledge that parents have about their child and family (Cavonius-Rintahaka et al., 2020). The more systematic approach to combine psychoeducation, practical, and emotional guidance, along with dialogical elements, makes DFG a novel approach compared to other available interventions. DFG provides personalized support during a six-session semi-structured program, allowing new perspectives and insights to be found. The reflective dialogue approach used in DFG enables family members and professionals to initiate "a mutual learning process," in line with the concepts presented by Seikkula and Trimble (2005). Of particular note is that while it is important to teach parents effective parenting strategies, many parents simply need space to discuss their worries, thoughts, and feelings (Evans et al., 2015; Raitio et al., 2015).

A pilot study (Cavonius-Rintahaka et al., 2019) was performed to obtain knowledge about parents' experiences and hopes regarding the help they received from health professionals. Families taking part in the pilot study (29 mothers and 17 fathers) received ordinary clinical treatment for the child and were not provided with any family intervention. The results indicate a strong positive correlation between family functioning and family health $(r=0.75, n=46, p<0.001)$ and further reveal that managing as a parent in daily life, having good self-confidence as a parent, and how the relationship between parents works need attention when developing interventions for families with a child with NDD. In the study, the parents also expressed their need for dialogue, psychoeducation, and for concrete guidance. These findings have been taken into consideration in the development of DFG, and results from other studies have also been taken into account during the development and implementation process (Barlow \& Stewart-Brown, 2000; Barlow et al., 2014, 2016; Bearss et al., 2015; Dretzke et al., 2009; Factor et al., 2019; Farmer \& Reupert, 2013; Peasgood et al., 2016; Trillingsgaard et al., 2014).

Because DFG is a new family intervention, there is limited knowledge and only subjective opinions about aspects of its effects in clinical practice. It is therefore important to study the effects of DFG regarding family functioning, family health, and social support in daily life. It is particularly interesting to examine whether DFG meets the needs and expectations of families with a child with NDD to the extent expected. The aim of the present research is to study the effects of DFG based on parent reports regarding family functioning, family health, and social support.

\section{Method}

\section{Participants}

The original study design plan was to include fifty families in this study. This decision was connected to a calculation based on the realistic possibility of collecting target families who were attending the neuropsychiatric unit over a 2-year period of time. Seventy-nine $(N=79)$ families met the inclusion criteria during the data collection period (2016-2018). Of these, twenty-nine refused to participate, and their reasons for refusal included problems with schedules $(n=17)$, a long distance to the clinic $(n=3)$, parents feeling they had no need for/no interested in DFG $(n=5)$, other outpatient clinic visits coming up $(n=3)$, and language issues $(n=1)$. The recruitment period ended once fifty families had given their informed consent to the study during the data collection period. Both parents from each family were given the opportunity to attend. From these fifty families $(n=50)$, sixty parents participated in the study at baseline. Forty-two $(n=42)$ families and fiftytwo parents $(n=52)$ completed both phases of the study (baseline T1 and 3 months follow-up T2).

The study participants were families with children referred to a neuropsychiatric unit at a university clinic that provides multidisciplinary assessments and rehabilitation plans through a team of child neurologists, child psychiatrists, (neuro-)psychologists, nurses, occupational therapists, language therapists, and social workers. Interventions and the rehabilitation of the child can be carried out either within the hospital, or at a clinic within the primary health care system.

Parents included in this study had a child with at least one diagnosis falling under the NDD umbrella (ADHD, ASD, tic disorders, speech and language disorders, specific learning disorders, specific developmental motoric or psychiatric disorders, delayed milestones) and aged between 4 and 16 years old. An additional criterion for inclusion in the study was that parents had adequate Finnish language skills and that they were the biological parents, caregivers, or stepparents of the child, and living with the child during ordinary day-to-day life.

The intervention group and comparison group consisted of a total of 52 parents at baseline. Of these, 30 parents were in the intervention group and 22 parents in the comparison group. The mean age of the parents at baseline was 38 years (SD 5), with the mean age of parents in the intervention group being 36.7 (SD 4.9) and the comparison group 38.7 (SD 5.3). In both groups, the median number of children was 2 . The minimum and maximum number of children was 1 and 6 in the intervention group, and 1 and 5 in the comparison group (Table 1). There were no 
Table 1 Baseline demographics of the parents taking part in intervention group $(n=30)$ and comparison group $(n=22)$

\begin{tabular}{|c|c|c|c|c|c|c|c|}
\hline \multirow[b]{2}{*}{ Background variables } & \multicolumn{2}{|c|}{$\begin{array}{l}\text { All partici- } \\
\text { pants }\end{array}$} & \multicolumn{2}{|c|}{$\begin{array}{l}\text { Interven- } \\
\text { tion group }\end{array}$} & \multicolumn{2}{|c|}{$\begin{array}{l}\text { Compari- } \\
\text { son group }\end{array}$} & \multirow[b]{2}{*}{$p$ value $^{1}$} \\
\hline & $n$ & $\%$ & $n$ & $\%$ & $n$ & $\%$ & \\
\hline Gender & & & & & & & 0.717 \\
\hline Father & 18 & 34.6 & 11 & 36.7 & 7 & 31.8 & \\
\hline Mother & 34 & 65.4 & 19 & 63.3 & 15 & 68.2 & \\
\hline Age (years) & & & & & & & 0.376 \\
\hline$<38$ & 25 & 48.1 & 16 & 53.3 & 9 & 40.9 & \\
\hline$\geq 38$ & 27 & 51.9 & 14 & 46.7 & 13 & 59.1 & \\
\hline Marital status & & & & & & & 0.559 \\
\hline Married/cohabiting & 38 & 73.1 & 21 & 70.0 & 17 & 77.3 & \\
\hline Do not live together & 14 & 26.9 & 9 & 30.0 & 5 & 22.7 & \\
\hline Quality of the relationship between parents & & & & & & & 0.613 \\
\hline Excellent/good & 31 & 59.6 & 17 & 56.7 & 14 & 63.6 & \\
\hline Moderate/poor/very poor & 21 & 40.4 & 13 & 43.3 & 8 & 36.4 & \\
\hline Basic education & & & & & & & 0.175 \\
\hline Comprehensive school & 16 & 30.8 & 7 & 23.3 & 9 & 40.9 & \\
\hline Matriculation examination & 36 & 69.2 & 23 & 76.7 & 13 & 59.1 & \\
\hline Professional education & & & & & & & 0.756 \\
\hline University degree & 32 & 61.5 & 19 & 63.3 & 13 & 59.1 & \\
\hline College level degree or lower & 20 & 38.5 & 11 & 36.7 & 9 & 40.9 & \\
\hline Number of children & & & & & & & 0.618 \\
\hline 1 child & 10 & 19.2 & 7 & 23.3 & 3 & 13.6 & \\
\hline 2 children & 25 & 48.1 & 13 & 43.3 & 12 & 54.5 & \\
\hline$\geq 3$ children & 17 & 32.7 & 10 & 33.3 & 7 & 31.8 & \\
\hline $\begin{array}{l}\text { Other members of the family with neurodevelopmen- } \\
\text { tal disorders or diagnoses }\end{array}$ & & & & & & & 0.284 \\
\hline Yes & 15 & 31.9 & 10 & 38.5 & 5 & 23.8 & \\
\hline No & 32 & 68.9 & 16 & 61.5 & 16 & 76.2 & \\
\hline Parents' self-reported health & & & & & & & 0.959 \\
\hline Very good /good & 40 & 76.9 & 23 & 76.7 & 17 & 77.3 & \\
\hline Moderate/poor/very poor & 12 & 23.1 & 7 & 23.3 & 5 & 22.7 & \\
\hline Managing as a parent in daily life & & & & & & & 0.516 \\
\hline Extremely well/quite well & 28 & 53.8 & 15 & 50.0 & 13 & 59.1 & \\
\hline Moderate/rather/Extremely poor & 24 & 46.2 & 15 & 50.0 & 9 & 40.9 & \\
\hline Having long-term illness or neuropsychiatric disorder & & & & & & & 0.146 \\
\hline Yes & 15 & 28.8 & 11 & 36.7 & 4 & 18.2 & \\
\hline No & 37 & 71.2 & 19 & 63.3 & 18 & 81.8 & \\
\hline
\end{tabular}

${ }^{1}$ Chi-square test statistically significant differences in the background variables of the parents between the intervention group and the comparison group (Table 1).

The characteristics of the children in intervention and comparison groups were quite similar in both groups (Table 2). The mean age of the children was 6.1 (SD 1.5) in the intervention group and 7.1 in the comparison group (SD 2.6, $\mathrm{Q}_{1} 5, \mathrm{Q}_{3}$ in intervention group 7, $\mathrm{Q}_{3}$ in comparison group 8). The minimum age of children in both groups was 4 , and maximum age was 10 in the intervention group and 14 in the comparison group. The median age of the child when parents had first raised concern about the child's neuropsychiatric problems was 2.5 in the intervention group $\left(\mathrm{Q}_{1} 2, \mathrm{Q}_{3} 3\right)$ and 3 in the comparison group $\left(\mathrm{Q}_{1} 1.7, \mathrm{Q}_{3} 4\right)$. The mean number of children's hospital or clinic appointments before the first appointment at a university neuropsychiatry clinic was 3.9 in the intervention (SD 2.7) and 5.6 in the comparison group (SD 4.0). Most of the children had ADHD or ASD as their main diagnosis, but comorbidities were also common. 
Table 2 Demographics of the children with NDD in families taking part in the study

\begin{tabular}{|c|c|c|c|c|c|c|c|}
\hline \multirow[b]{2}{*}{ Background variables } & \multicolumn{2}{|c|}{ All children } & \multicolumn{2}{|c|}{ Intervention group } & \multicolumn{2}{|c|}{ Comparison group } & \multirow[b]{2}{*}{$p$ value } \\
\hline & $n$ & $\%$ & $n$ & $\%$ & $n$ & $\%$ & \\
\hline Gender & & & & & & & $0.161^{1}$ \\
\hline Girl & 10 & 19.2 & 8 & 26.7 & 2 & 9.1 & \\
\hline Boy & 42 & 80.8 & 22 & 73.3 & 20 & 90.9 & \\
\hline Age (years) & & & & & & & 0.523 \\
\hline$<7$ & 31 & 59.6 & 19 & 63.3 & 12 & 54.5 & \\
\hline$\geq 7$ & 21 & 40.4 & 11 & 36.7 & 10 & 45.5 & \\
\hline Child's daytime activity & & & & & & & 0.051 \\
\hline In daycare & 40 & 76.9 & 26 & 86.7 & 14 & 63.6 & \\
\hline At school & 12 & 23.1 & 4 & 13.3 & 8 & 36.4 & \\
\hline Diagnose of the child & & & & & & & - \\
\hline Attention-deficit/hyperactivity disorder & 14 & 26.9 & 9 & 30.0 & 5 & 22.7 & \\
\hline Autism spectrum disorder (e.g., Aspergers syndrome) & 11 & 21.2 & 6 & 20.0 & 5 & 22.7 & \\
\hline Delayed milestone & 10 & 19.2 & 8 & 26.7 & 2 & 9.1 & \\
\hline Speech and language disorders & 6 & 11.5 & 4 & 13.3 & 2 & 9.1 & \\
\hline Specific learning disorder & 4 & 7.7 & - & - & 4 & 18.2 & \\
\hline Other (motoric or psychiatric problems, unclear) & 7 & 13.5 & 3 & 10.0 & 4 & 18.2 & \\
\hline First concern towards the child's neuropsychiatric problems & & & & & & & 0.516 \\
\hline $1-2$ years & 24 & 46.2 & 15 & 50.0 & 9 & 40.9 & \\
\hline$>2$ & 28 & 53.8 & 15 & 50.0 & 13 & 59.1 & \\
\hline How the child's NDD problems affect his/her daily life & & & & & & & - \\
\hline No symptom/hardly any symptoms & 3 & 5.8 & 1 & 3.3 & 2 & 9.1 & \\
\hline Symptoms occasionally & 5 & 9.6 & 2 & 6.7 & 3 & 13.6 & \\
\hline Symptoms often & 22 & 42.3 & 15 & 50.0 & 7 & 31.8 & \\
\hline Symptoms disturbing all the time & 22 & 42.3 & 12 & 40.0 & 10 & 45.5 & \\
\hline Earlier visit to the clinic/hospital & & & & & & & 0.376 \\
\hline Yes & 25 & 48.1 & 16 & 53.3 & 9 & 40.9 & \\
\hline No & 27 & 51.9 & 14 & 46.7 & 13 & 59.1 & \\
\hline
\end{tabular}

${ }^{1}$ Fisher's exact test, otherwise chi-square test

\section{Procedure}

\section{Study design}

Parents who attended the neuropsychiatric unit with their child for the first time during the data collection period were asked to take part in the study if they met the inclusion criteria. A research assistant nurse at the unit gave oral and written information to parents about the study, including information about the DFG family intervention.

Families who gave their consent to participate in the study filled in the baseline questionnaire and were alternately allocated into an intervention group or comparison group by a research assistant nurse. Families included in the intervention group were provided with DFG with an immediate starting point (baseline) simultaneous with ordinary clinical treatment, while the families in the comparison group only received ordinary clinical treatment. The randomization in this study meant that every second family was placed in an intervention group and every second family in the comparison group. However, the comparison group was given an opportunity to be provided with DFG after a 3-month waiting period. The parents could not choose which group they were assigned to, and the parent questionnaires completed at baseline did not affect which group the families were placed in. The ordinary clinical treatment at the unit was mainly focused on assessing children to clarify their diagnosis, and to plan the child's treatment and rehabilitation. Collaborating with parents is crucial when proceeding with a child's assessment and rehabilitation plan, but family interventions were not part of children's routine interventions at the unit. If needed, parents and siblings were also recommended to seek help from primary healthcare.

\section{Data Collection}

Baseline data (T1) were collected from both groups immediately after they had given their oral and written consent to 
participate in the study (Fig. 1). Randomization had already been completed in advance, and when giving their consent, the parents already knew whether they had been placed into the intervention group or the comparison group. The difference between the two groups was that the DFG intervention was immediately launched for the families in the intervention group, whereas those in the comparison group were told that they had to wait 3 months before gaining access to the intervention. However, the impact of the waiting list approach can cause different effects on outcomes and thus needs to be noticed (Cunningham et al., 2013; Mohr et al., 2009).

DFG is a family intervention tailored specifically for families with a child with NDD. The development process is based on clinical experience, practice, theory-based research, and a pilot study (Cavonius-Rintahaka et al., 2020). The aim of DFG is to help all the family members receive knowledge and gain an understanding of NDD/ESSENCE and to provide a reflective space for family members to discuss their worries, thoughts, and feelings. The DFG collaborative working process with family members lasts over six meetings (90 min per session) which take place within a 3-month period. The first intervention session begins with dialogue between the DFG therapist and parents, followed by an initial plan. The following five sessions are tailored together with the parents, depending on their needs, questions, daily demands, and hopes concerning the issues to be discussed during the common DFG process. Themes addressed by the parents are seen as the most important, although a DFG manual also includes suggested themes for each session and provides a structure for the DFG intervention process. The themes included in the manual are: Your family, What does NDD mean for your child, The child's development issues related to NDD, Demands in daily life, Resources in your family, Networks, Communication in your family, Relationships between family members, Sibling issues, Parents' reciprocal collaboration. The participants from the family (the child with NDD, siblings, and the parents) usually varied during the sessions, depending on the families' unique needs and the parents' wishes. Different combinations of family members participated in the six sessions.

The DFG structure is based on three guidance areas: psychoeducation (didactic element), practical guidance for daily life (skill-based practice), and emotional guidance. The practical guidance includes issues concerning daily life situations, helping parents find new solutions to the repetitive demands that emerge in the home environment. This is a skill-based practice that engages parents to a concrete level of how to behave and operate with the child. If needed, parents are guided on how to practice in their home environment and are provided with ideas about recommended changes that aim to make their everyday life run more smoothly. This emerging knowledge can be discussed together during the following intervention sessions. The emotional guidance includes sharing and listening to other families`stories and unique experiences, giving the participating families a space where every family member feels they are an equal, important, special, and unique individual. Alongside psychoeducation and guidance, the DFG therapist is interested in identifying the challenges and needs of all family members.

The DFG therapist and family members collaborate and seek effective parent strategies, skills to strengthen family members' relationships, and to engage in a dialogue to meet their individual goals. During the sessions, the DFG therapists gain knowledge about issues including the family system, family strengths, parenthood, the parents' relationship, family crises, and sibling reactions within the family. Parents share information regarding their daily demands, everyday lives, and the questions they have. When inviting family members to an open dialogue, professionals bring attention to these issues. Dialogue is an active process of speaking and listening. It is essential for professionals to be present in the moment, avoid speaking too much, or drawing conclusions too quickly. Every treatment meeting is unique and can be a shared emotional and healing experience. Supporting dialogue in a conversation encourages the participants to express their emotions and promotes a collective feeling of trust. Dialogue also leads to finding a shared language, and
Fig. 1 Study design and data collection
Measure schedule: baseline, 0 months (T1) RANDOMIZATION INTERVENTION GROUP

(30 parents from 23 families)

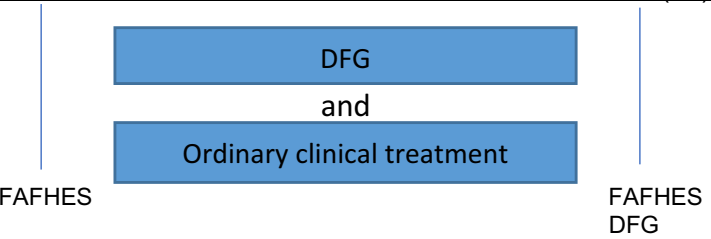

Ordinary clinical treatment
COMPARISON GROUP

(22 parents from 19 families) 
new ways of understanding problems can emerge (Seikkula $\&$ Trimble, 2005).

We believe that professionals need to find a balance between psychoeducation and having the sensitivity to make sure that the voices of each family member are heard. DFG differs from many other interventions in that it involves collaborating with all family members, not only the child with NDD or the parents. According to parents with children with NDD, personalized support for the entire family is an important aspect when addressing family health (CavoniusRintahaka et al., 2019).

Both medical and nursing knowledge are required to understand the complexity of NDD (Thapar et al., 2017) and ESSENCE (Gillberg, 2010). The DFG therapist possesses the competence required to transform this knowledge concerning NDD symptoms into practical guidance for families, in order to help them in their daily lives. DFG involves using traditional theory-based elements stemming from family therapy as an open dialogue (Seikkula \& Trimble, 2005), reflection (Weingarten, 2016), and systems therapy (Haefner, 2014).

Health care professionals, including registered nurses and social workers, participated in a three-day training program before being allowed to deliver DFG to families taking part in this study. Motivation and a willingness to attend were important factors when selecting professionals for this training. All professionals had a minimum of 3 years working history in neuropsychiatry. Supervision and consultation for the professionals was regularly made available during the study by the researcher. Individual qualifications and competence need to be given attention when studying the effect of interventions (Firth et al., 2020). In this study, these factors were considered during the recruitment and implementation phases, although the professionals attending the DFG training were nurses and social workers, not psychotherapists. While the researcher was the one providing the professionals with the DFG training, she was not in direct contact with the families and did not deliver DFG to the study participants.

\section{Measures}

The FAFHES instrument (Astedt-Kurki et al., 2002, 2004, 2009) was originally developed for patients with cardiac disease and their family members, and previous research has investigated the associations between social support for the family of adult cardiac patients and family functioning and perceived family health. FAFHES provides a reliable and valid instrument (Astedt-Kurki et al., 2009) and has been used in different contexts in various studies (Hakio et al., 2015; Lepistö et al., 2017). The FAFHES instrument was modified and tested in a pilot study and has been deemed applicable for families with children with NDD (CavoniusRintahaka et al., 2019).
The FAFHES instrument contains three dimensions: family functioning (19 items), family health ( 23 items), and social support provided by professionals ( 21 items). All the items are measured on a Likert scale ranging from 1 to 6 (I disagree totally, I disagree, I disagree somewhat, I agree somewhat, I agree, I agree totally). Family functioning, family health, and social support were seen as poor if the median was $1.00-2.7$, moderate if it was $2.8-4.5$, and good if it was 4.6-6.0 (Lepistö et al., 2017).

The DFG instrument was developed for this study to obtain information and parents' experiences about the DFG family intervention. The instrument contains 14 items. Questions concerning the number of sessions and the time spent on them were included as "Is six sessions the right number of sessions?" (Yes/No) and "How many sessions are suitable for DFG, according to you?" $(1=1,2=2 \ldots \ldots 6=6)$. Questions about the content and recommendation of DFG sessions included: "Did you get practical tips for daily life?" ( $1=$ yes absolutely $\ldots .0 .5=$ not at all $)$ and "Would you recommend DFG to other parents?" $(1=$ yes absolutely...0.4= no). One open-ended question was included in the DFG instrument: "Could you describe your experiences, comments and/ or ideas about how to improve DFG?". Parents filled out the instrument after completing the DFG process (six meetings).

A session checklist was used to monitor adherence to the identified themes and functions as a fidelity test to ensure that the therapist is delivering the program according to standards in line with the manual and their DFG training. The checklist also helped the professionals navigate through DFG, giving them structure, and reminding them to bring up certain important themes with the families. Professionals working with families during DFG sessions filled in the checklist after every finalized DFG process.

Demographic data were collected at the baseline stage of the study. The demographic data for parents were obtained in the first section of the FAFHES parent questionnaire including gender, age, marital status, quality of relationship between parents (extremely good, good, average, poor, extremely poor), basic education, professional education, number of children, other members of the family having NDD or related diagnoses, parents' self-reported health (extremely good, good, average, poor, extremely poor), and managing as a parent in daily life (extremely good, good, average, poor, extremely poor). The demographic data of children concerned their gender, age, the child's daytime activity, diagnosis on referral, parents' first concerns regarding the child's neuropsychiatric problems, the effect of the child's NDD on his/her daily life, and the child's earlier visits to the clinic. In addition to parent questionnaires, official medical reports were used to include the diagnosis of the children in the baseline demographics. The diagnoses of the children were defined by medical doctors and pre-established (diagnosis already on referral) or established during 
the study at the neuropsychiatric clinic. Potential additional diagnoses received after the study period were not included. Both parents from the same family had the opportunity to fill out their own FAFHES and DFG instrument, which were completed when visiting the unit.

\section{Data Analyses}

Statistical analysis was carried out using IBM SPSS Statistics for Windows version 27. The total scores for the three FAFHES variables were calculated by summing the score for all the items in the variable and dividing the sum by the number of items. The internal consistency of the scale was evaluated using Cronbach's alpha coefficients, with results ranging from 0.86 to 0.96 . The Kolmogorov-Smirnov test was applied to verify that the FAFHES sum variables were normally distributed. The distribution of FAFHES in the intervention group and comparison group was checked using the Shapiro-Wilk test. Nearly all had a normal distribution, except for the social support of comparison group at T1.

The chi-square test or Fisher's exact test was used to determine whether a difference exists between the intervention group and comparison group and the demographic variables. While some categories of demographic variables were small, the relationship between dependent variables (FAFHES) and demographic variables was analyzed using the Mann-Whitney $U$ test or the Kruskal-Wallis $H$ test with Bonferroni correction. A repeated measures analysis of variance (ANOVA) was used to examine the effect of time between the intervention and comparison group. The level of significance $(p)$ was set as $\leq 0.05$.

The parents also produced qualitative data by reporting their perceptions in writing more freely in response to one open-ended question: "Could you describe your experiences, comments and/or ideas about how to improve DFG?". The responses to this additional open-ended question from the DFG instrument were analyzed using content analysis (Graneheim et al., 2017). The content analysis followed a procedure using inductive content analysis, and therefore the variables were not identified in advance. The qualitative analysis began by reading parents' written responses, and frequent references to questions addressed in this study were highlighted. This was followed by an identification of similar sentences. Similar references were classified as a "subcategory" (grouping and combining similar or related answers). These subcategories were named relating to the actual content and present parents' opinions and hopes formulated to the upcoming themes. The last step in the content analysis was to create "main categories" based on "subcategories" by analyzing similarities and differences relating to the content. The results are presented as five main categories.

The researcher monitored the DFG session checklists, filled by the professionals after every finalized DFG process.

\section{Results}

\section{Associations Between Background Variables and FAFHES at Baseline}

At baseline, those parents who felt that the quality of the relationship between parents was good or excellent $(\mathrm{Md}$ $\left.4.9, \mathrm{Q}_{1} 4.4, \mathrm{Q}_{3} 5.2\right)$ had better family functioning ( $U 135.5$, $p<0.001)$ than those parents who felt that the quality of the relationship was moderate, poor, or very poor $\left(\mathrm{Md} 3.8, \mathrm{Q}_{1}\right.$ 3.6, $\mathrm{Q}_{3} 4.5$ ). Similarly, the parents who felt that the quality of the relationship between the parents was good or excellent $\left(\mathrm{Md} 4.3, \mathrm{Q}_{1} 3.8, \mathrm{Q}_{3} 4.7\right)$ had better family health $(U 123.5$, $p<0.001)$ than those parents who felt that the quality of the relationship was moderate, poor, or very poor $\left(\mathrm{Md} 3.7, \mathrm{Q}_{1}\right.$ 3.4, $\left.\mathrm{Q}_{3} 3.8\right)$.

At baseline, the parents who reported managing extremely well or quite well as a parent in their daily life (Md 5.0, $\left.\mathrm{Q}_{1} 4.6, \mathrm{Q}_{3} 5.4\right)$ had better family functioning ( $U$ 93.5, $p<0.001)$ than those parents who reported managing moderately or rather or extremely poorly as parent in their daily life (Md 3.8, $\left.\mathrm{Q}_{1} 3.7, \mathrm{Q}_{3} 4.4\right)$. Similarly, those parents who reported managing extremely well or quite well as a parent in their daily life $\left(\mathrm{Md} 4.4, \mathrm{Q}_{1} 3.8, \mathrm{Q}_{3} 4.7\right)$ had better family health $(U 137.5, p=0.000)$ than those parents who reported managing moderately or rather or extremely poorly as parent in daily life $\left(\mathrm{Md} 3.7, \mathrm{Q}_{1} 3.3, \mathrm{Q}_{3} 3.9\right)$.

\section{The Effect of DFG on Family Functioning, Family Health, and Social Support}

There was a significant within-subjects effect of time on family health $(F(1,50)=10.2, p=0.002$, effect size $=0.169)$ and social support $(F(1,50)=52.8, p<0.001$, effect size $=0.513$ ), indicating that family health and social support increased in both groups over time. However, there was a significant between-subjects effect of group $(F(1,50)=6.1$, $p=0.017$, effect size 0.108$)$ and interaction between time and group $(F(1,50)=5.6, p=0.022$, effect size $=0.100)$ on social support, indicating that there was difference between groups and that social support increased more in the intervention group than in the control group (Table 3 ).

\section{Participant's Perception of DFG}

Parents filled out the DFG instrument during the last DFG session. Most parents (96\%) taking part in this study felt that DFG was provided at an appropriate time for them, although some were provided with it immediately after the child's appointment at the clinic, and others after waiting for a 3-month period. In the intervention and comparison 
Table 3 ANOVA results for FAFHES

\begin{tabular}{|c|c|c|c|c|c|c|c|c|c|c|c|c|c|}
\hline \multirow{3}{*}{$\begin{array}{l}\text { Outcome measure } \\
\text { FAFHES }\end{array}$} & \multicolumn{2}{|c|}{ Intervention group } & \multicolumn{2}{|c|}{ Comparison group } & \multicolumn{6}{|c|}{ Within-subjects effects } & \multirow{2}{*}{\multicolumn{3}{|c|}{$\frac{\mathrm{m}}{\text { Group }}$}} \\
\hline & \multirow{2}{*}{$\begin{array}{l}\text { Baseline } \\
\text { Mean (SD) }\end{array}$} & \multirow{2}{*}{$\begin{array}{l}3 \text { month } \\
\text { Mean (SD) }\end{array}$} & \multirow{2}{*}{$\begin{array}{l}\text { Baseline } \\
\text { Mean (SD) }\end{array}$} & \multirow{2}{*}{$\begin{array}{l}3 \text { month } \\
\text { Mean (SD) }\end{array}$} & \multicolumn{3}{|l|}{ Time } & \multicolumn{3}{|c|}{ Time*Group } & & & \\
\hline & & & & & $\boldsymbol{F}$ & Sig & $\eta_{p}^{2}$ & $\boldsymbol{F}$ & Sig & $\eta_{p}^{2}$ & $F$ & Sig & $\eta_{p}^{2}$ \\
\hline Family Functioning & $4.44(0.74)$ & $4.39(0.77)$ & $4.63(0$. & $4.60(0.78)$ & 0.538 & & 70.011 & 0.016 & 0.900 & 0.000 & 0.916 & 0.343 & 0.018 \\
\hline Family Health & $3.89(0.52)$ & $4.13(0.60)$ & $4.24(0.63)$ & $4.30(0.65)$ & 10.188 & & 20.169 & 3.504 & 0.067 & 0.065 & 2.718 & 0.105 & 0.052 \\
\hline Social Support & $4.10(0.68)$ & $5.17(0.55)$ & $3.93(0.99)$ & $4.48(0.77)$ & 52.757 & $<0$ & 10.513 & 5.550 & 0.022 & 0.100 & 6.074 & 0.017 & 0.108 \\
\hline
\end{tabular}

$\eta_{\mathrm{p}=\text { partial eta square }}^{2}$

group, the parents felt that the optimal time for starting the DFG intervention would be immediately or 1 month after the child's first visit to the clinic. Six sessions are usual for DFG, and this was seen as adequate for most (86\%) parents. All the parents $(100 \%)$ felt that all of the family members had been taken into consideration during the DFG sessions. Parents felt (yes absolutely, or yes 96\%) that they had received advice and practical guidance, and that the DFG had helped them to manage better with their child with NDD (very much or much $89 \%$ ). The parents taking part in this study also recommended (yes absolutely, or yes 100\%) DFG as a suitable intervention to be delivered to other families (Table 4).

\section{Qualitative Data Results}

The one open-ended question in the DFG questionnaire constitutes the qualitative data results, which are presented as five main categories, including subcategories. The first main category "Practical guidance for daily life" included subcategories of "Experience of getting practical guidance" and "New procedure models for daily life". This included parents' expressions such as "We experienced DFG very positively. We received answers and solutions on how to deal everyday difficulties" and "We got a lot of practical ideas to take home."

The second main category of "Being heard" included the subcategories of "Good parent and family discussions during the DFG sessions" and "Experience of professionals listening to parents." Parents felt that they had been given full attention and expressed it with sentences such as: "It felt great that we were listened to, whenever we had the need to talk," "The atmosphere was wonderful, allowing us to be ourselves and it felt genuine," "Our concerns were heard and now we have survival strategies."

The third main category "Getting information" included the subcategories of "Experience of getting information as parents" and "Experience of getting new understanding as parents." Quotes from parents included: "This was a good experience, which helped us understand the child's situation better..." and "We got a lot of new ideas, information about the NDD symptoms, and support."

The fourth main category "Positive feedback about own parenthood" included the subcategory of "Experience of getting positive feedback as parents." This category was explained by comments such as "The positive feedback strengthened our self-esteem as parents" and "It is nice to get feedback about your own parenthood. You do not get it very often, at least not as much as in DFG."

The fifth main category of "DFG was a needed and rewarding experience" included subcategories of "DFG is a positive experience, getting attention as a family." Quotes from parents included: "We experienced DFG as a positive and relaxing experience" and "All six meetings were good and helpful."

Improvement ideas presented by the parents were, for example, that DFG could include more than six sessions, and that evening sessions would be appreciated. A few parents also hoped that the DFG therapists would make home visits and offer help in their home environment.

The analyses of the checklists used in this study verify that all (100\%) DFG programs have been implemented to families according to protocol and the requirement of the manual.

\section{Discussion}

The aim of this research was to study the effects of the DFG intervention based on parents' reports regarding family functioning, family health, and social support, using FAFHES and DFG instruments. These randomized families were compared between intervention group and comparison group. Surprisingly, families in both groups reported family functioning, family health, and social support as moderate or good already at baseline. Referring to previous studies made in these target families (Caicedo, 2014; Craig et al., 2016; Duarte et al., 2005), getting such relatively good findings concerning parents experiences of family functioning and family health already at the baseline was unexpected. 
Table 4 Participants' $(n=29)$ assessment taking part of on the last DFG session

\begin{tabular}{|c|c|c|}
\hline \multirow[b]{2}{*}{ DFG instrument } & \multicolumn{2}{|c|}{$\begin{array}{l}\text { Inter- } \\
\text { vention } \\
\text { group }\end{array}$} \\
\hline & $n$ & $\%$ \\
\hline \multicolumn{3}{|l|}{ Who gave the information about DFG } \\
\hline Doctor & 6 & 20.7 \\
\hline Nurse & 23 & 79.3 \\
\hline \multicolumn{3}{|c|}{ Was the DFG at appropriate time for your family } \\
\hline Yes & 28 & 96.6 \\
\hline No & 1 & 3.4 \\
\hline \multicolumn{3}{|l|}{ When is the right time for DFG } \\
\hline At once & 18 & 64.3 \\
\hline After 1 month & 9 & 32.1 \\
\hline After $2-4$ months & 1 & 3.6 \\
\hline \multicolumn{3}{|l|}{ How many DFG sessions did you have } \\
\hline $1-5$ & 1 & 3.4 \\
\hline 6 (ordinary for DFG) & 28 & 96.6 \\
\hline \multicolumn{3}{|l|}{ Is six DFG sessions adequate } \\
\hline Yes & 25 & 86.2 \\
\hline No & 4 & 13.8 \\
\hline \multicolumn{3}{|c|}{ What is adequate number of DFG sessions } \\
\hline $4-5$ & - & - \\
\hline 6 & 25 & 86.2 \\
\hline 7 or more & 4 & 13.8 \\
\hline \multicolumn{3}{|c|}{ Did you have DFG sessions outside the clinic } \\
\hline Yes & 2 & 6.9 \\
\hline No (usual in DFG) & 27 & 93.1 \\
\hline \multicolumn{3}{|l|}{ Are DFG sessions outside clinic needed } \\
\hline Yes & 9 & 32.1 \\
\hline No & 19 & 67.9 \\
\hline \multicolumn{3}{|l|}{ What is best time for one DFG session } \\
\hline $45 \min$ & 1 & 3.4 \\
\hline $60 \mathrm{~min}$ & 3 & 10.3 \\
\hline 90 min (ordinary for one DFG session) & 25 & 86.2 \\
\hline \multicolumn{3}{|c|}{ Who were delivering DFG sessions for your family } \\
\hline Nurse & 26 & 89.7 \\
\hline Social worker & 3 & 10.3 \\
\hline \multicolumn{3}{|c|}{ Were all family members taken into consideration } \\
\hline Yes & 29 & 100 \\
\hline No & - & - \\
\hline \multicolumn{3}{|c|}{ Do you recommend DFG sessions to other families } \\
\hline Yes, absolutely & 26 & 89.7 \\
\hline Yes & 3 & 10.3 \\
\hline \multicolumn{3}{|l|}{ Did you get practical advice and tips } \\
\hline Yes, absolutely & 16 & 55.2 \\
\hline Yes & 12 & 41.4 \\
\hline Maybe & 1 & 3.4 \\
\hline \multicolumn{3}{|c|}{$\begin{array}{l}\text { How much did DFG help you to manage with your } \\
\text { child }\end{array}$} \\
\hline Very much & 11 & 37.9 \\
\hline
\end{tabular}

Table 4 (continued)

\begin{tabular}{lll}
\hline DFG instrument & $\begin{array}{l}\text { Inter- } \\
\text { vention } \\
\text { group }\end{array}$ \\
\cline { 2 - 4 } Much & $n$ & $\%$ \\
A little & 15 & 51.7 \\
\hline
\end{tabular}

The results of this study indicate that there were greater improvements in social support for the DFG group, but no between group differences in relation to family health. This finding can be associated with the fact that the children with NDD in these families were university hospital treatment patients during this study. Moreover, the children in this study were quite young, and there were no parent reports of children having behavioral problems, nor ODD. Families taking part in this study were receiving ongoing care (ordinary clinical treatment) for their child, and this could explain the proportionally good baseline reports for both groups.

Although the families expressed moderate or good values already at baseline, there were still some positive changes in both groups concerning the experience of family health and social support compared to baseline. The main result of this study was that family health and social support increased in both groups, but in the intervention group, the change towards better health and support increased more compared to the comparison group. According to Johnston et al. (2012), there are many factors in the family environment, family relationship, and family psychology/dynamics that influence these target families.

The quality of the relationship between the parents was connected to family functioning and family health. Those families with excellent or good parental relationships also had better family functioning and family health. This result is in line with several studies (Craig et al., 2016; Duarte et al., 2005; Hartley \& Schultz, 2015; Hartley et al., 2010) reporting that the nature of NDD symptoms reflects and influences the whole family, including marital problems. Naturally, the stressful and demanding nature of NDD symptoms may elicit marital miscommunication and inconsistencies in parenting, or a low frustration tolerance between parents. Marital dysfunction was not profoundly examined in this study, but according to Hartley et al. (2010), the risk of divorce is significantly high in parents of children with autism and reminds us of the need to pay attention to the relationship of the parents during family interventions.

Obviously, the families in this study have children with a different range of NDD disorders. A child's behavior can evoke negative reactions between family members and result in dysfunctional parenting practices. Repetitive unsuccessful parental efforts to control the child's behavior can decrease 
the parent's self-esteem, emotional well-being, and negatively affect their parenting identity. The parents in this study expressed that positive feedback about their own parenthood was important and that DFG was a rewarding experience as a parent. It appears that getting positive feedback from professionals about one's parenthood and parental skills has strengthening impacts on parenthood identity. Also, the experience of getting practical guidance, having good discussions, and being heard during the DFG sessions seemed to be meaningful for parents.

Coping as parent in daily life was connected to family functioning, family health, and social support. The parents in the intervention group received advice and practical guidance to help them in their daily lives, and this helped them manage better with their child with NDD. This is in line with the study by Craig et al. (2016) which indicated that increasing parents' knowledge and skills can reduce stress and offer parents empowerment. Having enough knowledge as a parent can foster a sense of independence and give confidence in managing something that they had previously found to be difficult.

Based on several studies (Biederman \& Faraone, 2005; Chen et al., 2017; Hudziak et al., 2005; Tick et al., 2016a), due to a high heritability rate, there is an increased prevalence of the same kinds of symptoms or even diagnoses in parents and siblings of children with NDD. In this study, approximately one-third of the parents agreed that more than one family member had neurodevelopmental disorders, and several parents answered positively to the question concerning parents having long-term illness or a neuropsychiatric disorder themselves. According to Rucklidge et al. (2007), men and women with ADHD, regardless of gender, struggle significantly with their own psychosocial functioning.

The role of parental attributions in children's responses to treatment is essential. A study by Caicedo (2014) claims that families need interventions to improve health and functioning for both the parents and the children. In this study, nearly all the parents reported that all of the family members had been taken into consideration, and a family system perspective had been put into practice. Ansari et al. (2016) have also confirmed that relationships among individuals within the family are known to have a unique influence over the overall family system and that professionals can help parents in establishing positive thinking towards the child.

Nearly all the parents, including those in the comparison group, felt that the DFG intervention had been well-timed and that DFG should be delivered to families very quickly after the child's initial appointment at the clinic. It could be that families have already had the experience of struggling for several years, and a 3-month wait for DFG does not cause much of a problem in comparison. According to Moen et al. (2015), social support and support from community health services are strongly positively associated with family functioning. Thus, the knowledge of an upcoming DFG intervention can probably provide families with comfort and alleviate their feelings of stress to some degree.

It is well-known that the family environment is an important factor in the development of every child, and family dysfunction may serve as a risk factor that poses a bad influence on the child's development and presentations of NDD symptoms. It can be that a dialogic approach offers help to identify aspects of parenting that are demanding in families' daily life. The use of open dialogue (Seikkula \& Trimble, 2005 ) throughout the DFG intervention process allows professionals to confirm families' emotions, expectations, and disappointments. With the help of dialogue, family members get an opportunity to process and share their experiences, combined with psychoeducation and guidance in practical issues. This study supports the findings of Evans et al. (2015) that parents need space to discuss their worries and reflect on their thoughts and feelings. This can be considered as an important factor in family interventions. However, because only parents' perceptions were studied, the results of this study need to be seen as rather preliminary, and they can only be considered to determine the parents' perceptions of the acceptability and usefulness of DFG. Furthermore, as this study only provides limited information about the objective effects of DFG, there is a need for research using more objective, observational measures to further ascertain the effects of this intervention. Nevertheless, this study helped to reveal many interesting aspects and factors, and these could be evaluated in more detail by using a structured parental interview in addition to the FAFHES instrument.

\section{Limitations and Future Research}

The FAFHES instrument has been tested in studies since 2002 (Astedt-Kurki et al., 2002, 2009) and has been found to be a reliable tool in terms of construct validity and internal consistency, as well as to have good psychometric properties with a Cronbach's alpha for family functioning 0.92, family health 0.80 , and social support 0.98 (Astedt-Kurki et al., 2009). These values are in line with the values from the modified FAFHES instrument used in this study as at $\mathrm{T} 1$, family functioning was 0.90 , family health 0.86 , and social support 0.95 , and at $\mathrm{T} 2$ family functioning 0.92 , family health 0.88 , and social support 0.95 . Although the instrument was modified and tested in a pilot study and was deemed applicable for families of children with NDD (Cavonius-Rintahaka et al., 2019), it needs to be noted that the modified FAFHES instrument has been used only in these two studies.

However, because only parents' perceptions were studied, the results of this study need to be seen as rather preliminary, and they can only be considered to determine the parents' perceptions of the acceptability and usefulness of DFG. 
Furthermore, as this study only provides limited information about the objective effects of DFG, there is a need for research using more objective, observational measures to further ascertain the effects of this intervention. The most important area of future research is to examine the effects of DFG using objective child and parent outcome measures. Until then, the effects of DFG cannot be estimated reliably. Other limitations are the reliance on parental report measures and the fact that the comparison group was aware that they would receive the intervention at a later stage. Nevertheless, this study helped to reveal many interesting aspects and factors, and these could be evaluated in more detail by using a structured parental interview in addition to the FAFHES instrument.

All families included were clients of the same neuropsychiatric outpatient clinic at a university hospital, and therefore the results do not include any comparison between other outpatient clinics or hospitals. The parents in this study are representative concerning the focus group, because they all have a child with at least one NDD diagnosis. Moreover, the children became patients receiving ordinary care at the university hospital during this study, and the families were involved in the child's assessment and treatment plan at the baseline measure. Nevertheless, families drawn from several different clinics could provide wider knowledge about families with diverse baseline experiences.

Several studies reveal that families of children with NDD experience multiple challenges causing stress, burden, exhaustion, and emotional problems. However, the families included in this study were an atypical representation of parents with children with NDD, because surprisingly, all the families reported moderate or good family functioning, family health and social support at baseline. Hospital involvement can explain why the parents reported their level of family functioning to be at least moderate already at the baseline. These are limitations that need to be taken into consideration when reading the results, as the relatively good baseline family functioning and family health values most likely affect the 3-month follow-up values. Accordingly, this study may be seen as having limited capacity to produce knowledge about the effects of DFG only concerning families with relatively good baseline values for family functioning and family health.

In this study, randomization was carried out in an atypical way, as every second family that gave their consent to the study was placed in the intervention group and every second family to comparison group by a research assistant nurse. Using a random number generator would have been a more common form of randomization. According to Mohr et al. (2009), there is little agreement or consistency concerning the design and construction of control conditions, and yet it is known that different types of control conditions can produce significantly different effects on outcomes. Families in the comparison group were at the same time waiting for 3 months to initiate their DFG intervention. This can be considered as a limitation, as the knowledge of getting DFG later can affect parents' experiences and collected comparison group data. However, this was also an ethical decision, because it seemed important to give all families meeting the inclusion criteria in this study an opportunity to be provided with DFG.

The treatment used in this study (DFG) was manualized, its implementation monitored, a checklist was used during DFG by professionals, and the intervention was carried out by trained and supervised professionals (Cavonius-Rintahaka et al., 2020). The professionals worked in pairs when delivering the intervention. In this way, the DFG interventions provided to families were aimed to be homogeneous in quality and delivered in-line with the laid-out DFG intervention structure. The professionals received their DFG education from the same educator, and this made the training equal for implementers. These procedures can be seen as factors improving the intervention quality and reducing any variability among professionals. On the other hand, the impact of the professionals' implementing DFG cannot be completely ignored. According to Firth et al. (2020), interactions with professionals and differences between individual professionals make the study vulnerable, and differences in the skill levels of therapists are always possible. These therapist-related effects between those implementing DFG and family outcomes should be considered in the future delivery of DFG, and research conducted within this context. This may have implications on the application of research evidence, and the outcome and delivery of DFG.

In this study, although the children were taking part in the DFG sessions, they did not fill in their own questionnaires and the children's opinions are not featured in the results. The results therefore involve only the parents' perceptions, and the children's voices have not been heard, which is an issue regarding follow-up research. More research is needed using objective, observational measures to further ascertain the effects of this intervention. Furthermore, there is a need for knowledge about DFG's effectivity in families with low family functioning and family health at the baseline, and studies on whether this treatment is effective with other diagnostic, or disease groups would be of interest.

Support given during a 3-month period to the entire family can already increase families' experiences of family health and social support. Managing in daily life as a parent and the relationship between parents was associated with family functioning and family health. Responses from the DFG parent questionnaire report that practical guidance, information, dialogue between professionals and parents, and positive feedback on one's parenthood can be strengthening factors. According to the parents, the advice and practical guidance given in the intervention had helped 
them manage better with their child with NDD. Based on the parents' reports, it can be assumed that in addition to the information provided, it is important to offer parents an opportunity to engage in a dialogue about their experiences and the emotions they face in their daily life with the child. This study provides preliminary evidence that shows that parents can have positive perceptions of DFG. But as the results only present parents' perceptions of the acceptability and usefulness of DFG, larger-scale and more rigorous research is warranted to further ascertain the effects of this intervention.

Acknowledgements Our warmest thanks go to the many families who participated in this study, and the personnel working at the Helsinki University Hospital. The leaders of the hospital, as well as the clinicians proceeding with the DFG intervention with the families, made this study possible and helped to develop a family intervention model suitable for clinical use. Special thank you to Arja Voutilainen for her collaboration and support at the clinic. We also want to thank Professor Päivi Åstedt-Kurki and her copyright holders at Tampere University who gave permission to modify and use the FAFHES questionnaire for the studies concerning families with a child with NDD.

Author Contribution DCR: prepared the material, collected the data, analyzed the qualitative data, assisted with the quantitative data analyses, executed the study, and wrote the paper. MR: collaborated with design, analyzed the quantitative data, and wrote parts of the paper, collaborated with editing of the final manuscript. CG: contributed to study conception, design of the study and collaborated with editing of the final manuscript. EB: contributed to study conception, collaborated with design, and with editing of the final manuscript. ALA: contributed to study conception and design of the study, material preparations, analyzing and writing of the paper. All authors read and approved the final manuscript for submission.

Funding Helsinki University Hospital and Finnish Cultural Foundation have supported this study by contributing research fund. Reporting of the study was supported by the Nursing Research Center, Helsinki University Hospital.

Availability of Data and Materials The datasets used and analyzed during the current study are available from the corresponding author on reasonable request. To protect the confidentiality of the participants, the data are not publicly available due to privacy/ethical restrictions.

\section{Declarations}

Ethics Approval and Consent to Participate The ethical standards of the American Psychiatric Association and the Declaration of Helsinki were followed in this study (World Medical Association Declaration of Helsinki: ethical principles for medical research involving human subjects, 2013). The study was granted ethics committee approval before the onset of the study $(2012,2013,2015)$ from the Helsinki University Hospital ethical committee of psychiatry (nr:106/13/03/03/2012) and research approval from the University Hospital board was received in 2012,2013 , and 2015. This study was retrospectively registered with ClinicalTrials.gov with the identifier: NCT04892992 on May 18, 2021. All the procedures performed in the study are in accordance with the ethical standards of the institutional research committee and with the 1964 Helsinki Declaration and its later amendments. Informed consent to participate in this study was obtained both orally and in writing from participants (parents in the families) included in the study. The researcher was not involved in any way directly with the families and did not deliver DFG to the families taking part in this study, to maintain objectivity in this research process.

Conflict of Interest The authors declare no competing interests.

Open Access This article is licensed under a Creative Commons Attribution 4.0 International License, which permits use, sharing, adaptation, distribution and reproduction in any medium or format, as long as you give appropriate credit to the original author(s) and the source, provide a link to the Creative Commons licence, and indicate if changes were made. The images or other third party material in this article are included in the article's Creative Commons licence, unless indicated otherwise in a credit line to the material. If material is not included in the article's Creative Commons licence and your intended use is not permitted by statutory regulation or exceeds the permitted use, you will need to obtain permission directly from the copyright holder. To view a copy of this licence, visit http://creativecommons.org/licenses/by/4.0/.

\section{References}

Ansari, N. J., Dhongade, R. K., Lad, P. S., Borade, A., Yg, S., Yadav, V., Mehetre, A., \& Kulkarni, R. (2016). Study of parental perceptions on health \& social needs of children with neuro-developmental disability and its impact on the family. Journal of Clinical \& Diagnostic Research, Sc10(Sc20), 16-20. https://doi.org/10.7860/ jcdr/2016/22538.9039.

Astedt-Kurki, P., Tarkka, M.-T., Paavilainen, E., \& Lehti, K. (2002). Development and testing of a family nursing scale. Western Journal of Nursing Research, 24(5), 567-579.

Astedt-Kurki, P., Lehti, K., Tarkka, M. T., \& Paavilainen, E. (2004). Determinants of perceived health in families of patients with heart disease. Journal of Advanced Nursing, 48(2), 115-123.

Astedt-Kurki, P., Tarkka, M. T., Rikala, M. R., Lehti, K., \& Paavilainen, E. (2009). Further testing of a family nursing instrument (FAFHES). International Journal of Nursing Studies, 46(3), 350-359. https://doi.org/10.1016/j.ijnurstu.2008.01.008.

Barlow, J., \& Stewart-Brown, S. (2000). Behavior problems and groupbased parent education programs. Journal of Developmental and Behavioral Pediatrics: JDBP, 21(5), 356-370.

Barlow, J., Smailagic, N., Huband, N., Roloff, V., \& Bennett, C. (2014). Group-based parent training programs for improving parental psychosocial health. Cochrane Database of Systematic Reviews (5), Cd002020. https://doi.org/10.1002/14651858.CD002020.pub4.

Barlow, J., Bergman, H., Kornor, H., Wei, Y., \& Bennett, C. (2016). Group-based parent training programs for improving emotional and behavioral adjustment in young children. Cochrane Database of Systematic Reviews (8), Cd003680. https://doi.org/10.1002/ 14651858.CD003680.pub3.

Bearss, K., Johnson, C., Smith, T., Lecavalier, L., Swiezy, N., Aman, M., McAdam, D. B., Butter, E., Stillitano, C., Minshavi, N., Sukhodolsky, D. G., Mruzek, D. W., Turner, K., Neal, T., Hallett, V., Mulick, D. A., Green, B., Handen, B., Deng, Y., \& ...Scahill, L. (2015). Effect of parent training vs parent education on behavioral problems in children with autism spectrum disorder: A randomized clinical trial. JAMA, 313(15), 1524-1533. https://doi.org/ 10.1001/jama.2015.3150.

Biederman, J. (2006). Introduction: New developments in the treatment of attention-deficit/hyperactivity disorder. Journal of Clinical Psychiatry, 67(Suppl 8), 4-6. 
Biederman, J., \& Faraone, S. V. (2005). Attention-deficit hyperactivity disorder. Lancet, 366(9481), 237-248. https://doi.org/10.1016/ s0140-6736(05)66915-2.

Caicedo, C. (2014). Families with special needs children: Family health, functioning, and care burden. Journal of the American Psychiatric Nurses Association, 20(6), 398-407. https://doi.org/ 10.1177/1078390314561326.

Cavonius-Rintahaka, D., Aho, A. L., Voutilainen, A., Billstedt, E., \& Gillberg, C. (2019). Health, functionality, and social support in families with a child with a neurodevelopmental disorder - A pilot study. Neuropsychiatric Disease and Treatment, 15, 11511161. https://doi.org/10.2147/ndt.s195722.

Cavonius-Rintahaka, D., Aho, A. L., Billstedt, E., \& Gillberg, C. (2020). Dialogical Family Guidance (dfg) — Development and implementation of an intervention for families with a child with neurodevelopmental disorders. Nursing Open. https://doi.org/ 10.1002/nop2.627.

Chen, Q., Brikell, I., Lichtenstein, P., Serlachius, E., Kuja-Halkola, R., Sandin, S., \& Larsson, H. (2017). Familial aggregation of attention-deficit/hyperactivity disorder. Journal of Child Psychology and Psychiatry and Allied Disciplines, 58(3), 231-239. https://doi.org/10.1111/jcpp.12616.

Craig, F., Operto, F. F., De Giacomo, A., Margari, L., Frolli, A., Conson, M., Ivagnes, S., Monaco, S., \& Margari, F. (2016). Parenting stress among parents of children with Neurodevelopmental Disorders. Psychiatry Research, 242, 121-129. https:// doi.org/10.1016/j.psychres.2016.05.016.

Cunningham, J. A., Kypri, K., \& McCambridge, J. (2013). Exploratory randomized controlled trial evaluating the impact of a waiting list control design. BMC Medical Research Methodology, 13, 150. https://doi.org/10.1186/1471-2288-13-150.

Dretzke, J., Davenport, C., Frew, E., Barlow, J., Stewart-Brown, S., Bayliss, S., Taylor, R. S., Sandercock, J., \& Hyde, C. (2009). The clinical effectiveness of different parenting programs for children with conduct problems: A systematic review of randomized controlled trials. Child and Adolescent Psychiatry and Mental Health, 3(1), 7. https://doi.org/10.1186/1753-2000-3-7.

Duarte, C. S., Bordin, I. A., Yazigi, L., \& Mooney, J. (2005). Factors associated with stress in mothers of children with autism. Autism, 9(4), 416-427. https://doi.org/10.1177/1362361305 056081.

Evans, G., Wittkowski, A., Butler, H., Hedderly, T., \& Bunton, P. (2015). Parenting interventions in tic disorders: An exploration of parents' perspectives. Child: Care, Health and Development, 41(3), 384-396. https://doi.org/10.1111/cch.12212.

Factor, R. S., Ollendick, T. H., Cooper, L. D., Dunsmore, J. C., Rea, H. M., \& Scarpa, A. (2019). All in the family: A systematic review of the effect of caregiver-administered autism spectrum disorder interventions on family functioning and relationships. Clinical Child and Family Psychology Review, 22(4), 433-457. https:// doi.org/10.1007/s10567-019-00297-x.

Falk, N. H., Norris, K., \& Quinn, M. G. (2014). The factors predicting stress, anxiety, and depression in the parents of children with autism. Journal of Autism and Developmental Disorders, 44(12), 3185-3203.

Faraone, S. V., \& Larsson, H. (2019). Genetics of attention deficit hyperactivity disorder. Molecular Psychiatry, 24(4), 562-575. https://doi.org/10.1038/s41380-018-0070-0.

Faraone, S. V., Asherson, P., Banaschewski, T., Biederman, J., Buitelaar, J. K., Ramos-Quiroga, J. A., Rohde, L. A., Sonuga-Barke, E. J., Tannock, R., \& Franke, B. (2015). Attention-deficit/hyperactivity disorder. Nature Reviews Disease Primers, 1, 15020. https:// doi.org/10.1038/nrdp.2015.20.

Farmer, J., \& Reupert, A. (2013). Understanding autism and understanding my child with autism: An evaluation of a group parent education program in rural Australia. Australian Journal of Rural Health, 21(1), 20-27. https://doi.org/10.1111/ajr.12004.

Firth, N., Saxon, D., Stiles, W. B., \& Barkham, M. (2020). Therapist effects vary significantly across psychological treatment care sectors. Clinical Psychology \& Psychotherapy, 27(5), 770-778. https://doi.org/10.1002/cpp.2461.

Gillberg, C. (2010). The ESSENCE in child psychiatry: Early symptomatic syndromes eliciting neurodevelopmental clinical examinations. Research in Developmental Disabilities, 31(6), 1543-1551.

Graneheim, U. H., Lindgren, B. M., \& Lundman, B. (2017). Methodological challenges in qualitative content analysis: A discussion paper. Nurse Education Today, 56, 29-34.

Haefner, J. (2014). An application of Bowen family systems theory. Issues in Mental Health Nursing, 35(11), 835-841. https://doi. org/10.3109/01612840.2014.921257.

Hakio, N., Rantanen, A., Astedt-Kurki, P., \& Suominen, T. (2015). Parents' experiences of family functioning, health and social support provided by nurses - A pilot study in pediatric intensive care. Intensive and Critical Care Nursing, 31(1), 29-37.

Hartley, S. L., \& Schultz, H. M. (2015). Support needs of fathers and mothers of children and adolescents with autism spectrum disorder. Journal of Autism and Developmental Disorders, 45(6), 1636-1648. https://doi.org/10.1007/s10803-014-2318-0.

Hartley, S. L., Barker, E. T., Seltzer, M. M., Floyd, F., Greenberg, J., Orsmond, G., \& Bolt, D. (2010). The relative risk and timing of divorce in families of children with an autism spectrum disorder. Journal of Family Psychology, 24(4), 449-457. https://doi.org/ 10.1037/a0019847.

Hudziak, J. J., Derks, E. M., Althoff, R. R., Rettew, D. C., \& Boomsma, D. I. (2005). The genetic and environmental contributions to attention deficit hyperactivity disorder as measured by the Conners' rating scales-Revised. American Journal of Psychiatry, 162(9), 1614-1620. https://doi.org/10.1176/appi.ajp.162.9.1614.

Johnston, C., Mash, E. J., Miller, N., \& Ninowski, J. E. (2012). Parenting in adults with attention-deficit/hyperactivity disorder (ADHD). Clinical Psychology Review, 32(4), 215-228. https:// doi.org/10.1016/j.cpr.2012.01.007.

Lai, M. C., Lombardo, M. V., \& Baron-Cohen, S. (2014). Autism. Lancet, 383(9920), 896-910. https://doi.org/10.1016/s0140-6736(13) 61539-1

Lepistö, S., Ellonen, N., Helminen, M., \& Paavilainen, E. (2017). The family health, functioning, social support, and child maltreatment risk of families expecting a baby. Journal of Clinical Nursing, 26(15-16), 2439-2451. https://doi.org/10.1111/jocn.13602.

Michelson, D., Davenport, C., Dretzke, J., Barlow, J., \& Day, C. (2013). Do evidence-based interventions work when tested in the "real world?" A systematic review and meta-analysis of parent management training for the treatment of child disruptive behavior. Clinical Child and Family Psychology Review, 16(1), 18-34. https:// doi.org/10.1007/s10567-013-0128-0.

Moen, Ø. L., Hedelin, B., \& Hall-Lord, M. L. (2015). Parental perception of family functioning in everyday life with a child with ADHD. Scandinavian Journal of Public Health, 43(1), 10-17. https://doi.org/10.1177/1403494814559803.

Mohr, D. C., Spring, B., Freedland, K. E., Beckner, V., Arean, P., Hollon, S. D., Ockene, J., \& Kaplan, R. (2009). The selection and design of control conditions for randomized controlled trials of psychological interventions. Psychotherapy and Psychosomatics, 78(5), 275-284. https://doi.org/10.1159/000228248.

Morris-Rosendahl, D. J., \& Crocq, M. A. (2020). Neurodevelopmental disorders-the history and future of a diagnostic concept. Dialogues in Clinical Neuroscience, 22(1), 65-72. https://doi.org/10. 31887/DCNS.2020.22.1/macrocq.

Oerlemans, A. M., Burmanje, M. J., Franke, B., Buitelaar, J. K., Hartman, C. A., \& Rommelse, N. N. (2016). Identifying unique versus shared pre- and perinatal risk factors for ASD and ADHD 
using a simplex-multiplex stratification. Journal of Abnormal Child Psychology, 44(5), 923-935. https://doi.org/10.1007/ s10802-015-0081-0.

Okyar, E., \& Görker, I. (2020). Examining the autistic traits in children and adolescents diagnosed with attention-deficit hyperactivity disorder and their parents. BMC Psychiatry, 20(1), 285. https://doi. org/10.1186/s12888-020-02703-Z.

Paidipati, C. P., Deatrick, J. A., Eiraldi, R. B., Ulrich, C. M., \& Brawner, B. M. (2020). Family management in childhood attention deficit hyperactivity disorder: A qualitative inquiry. Journal of Pediatric Nursing, 52, 82-90. https://doi.org/10.1016/j.pedn. 2019.09.027.

Peasgood, T., Bhardwaj, A., Biggs, K., Brazier, J. E., Coghill, D., Cooper, C. L., Daley, D., De Silva, C., Harpin, V., Hodgkins, P., Nadkarni, A., Setyawan, J., \& Sonuga-Barke, E. J. (2016). The impact of ADHD on the health and well-being of ADHD children and their siblings. European Child and Adolescent Psychiatry, 25(11), 1217-1231. https://doi.org/10.1007/s00787-016-0841-6.

Pisula, E., \& Porebowicz-Dorsmann, A. (2017). Family functioning, parenting stress and quality of life in mothers and fathers of Polish children with high functioning autism or Asperger syndrome. PLOS ONE, 12(10), e0186536. https://doi.org/10.1371/journal.pone.0186536.

Posserud, M., Hysing, M., Helland, W., Gillberg, C., \& Lundervold, A. J. (2018). Autism traits: The importance of "co-morbid" problems for impairment and contact with services. Data from the Bergen Child Study. Research in Developmental Disabilities, 72, 275-283. https://doi.org/10.1016/j.ridd.2016.01.002.

Raitio, K., Kaunonen, M., \& Aho, A. L. (2015). Evaluating a bereavement follow-up intervention for grieving mothers after the death of a child. Scandinavian Journal of Caring Sciences, 29(3), 510 520. https://doi.org/10.1111/scs.12183.

Robert, C., Pasquier, L., Cohen, D., Fradin, M., Canitano, R., Damaj, L., Odent, S., \& Tordjman, S. (2017). Role of genetics in the etiology of autistic spectrum disorder: towards a hierarchical diagnostic strategy. International Journal of Molecular Sciences, 18(3). https://doi.org/10.3390/ijms18030618.

Rodriguez, G., Hartley, S. L., \& Bolt, D. (2019). Transactional relations between parenting stress and child autism symptoms and behavior problems. Journal of Autism and Developmental Disorders, 49(5), 1887-1898. https://doi.org/10.1007/s10803-018-3845-x.

Rommelse, N. N., Franke, B., Geurts, H. M., Hartman, C. A., \& Buitelaar, J. K. (2010). Shared heritability of attention-deficit/hyperactivity disorder and autism spectrum disorder. European Child and Adolescent Psychiatry, 19(3), 281-295. https://doi.org/10.1007/ s00787-010-0092-x.

Rucklidge, J., Brown, D., Crawford, S., \& Kaplan, B. (2007). Attributional styles and psychosocial functioning of adults with ADHD: Practice issues and gender differences. Journal of Attention Disorders, 10(3), 288-298. https://doi.org/10.1177/1087054706289942.

Schwartzman, J. M., Millan, M. E., Uljarevic, M., \& Gengoux, G. W. (2021). Resilience intervention for parents of children with autism: Findings from a randomized controlled trial of the AMOR Method. Journal of Autism and Developmental Disorders. https:// doi.org/10.1007/s10803-021-04977-y.

Seikkula, J., \& Trimble, D. (2005). Healing elements of therapeutic conversation: Dialogue as an embodiment of love. Family Process, 44(4), 461-475. https://doi.org/10.1111/j.1545-5300.2005. 00072.x.

Siebelink, N. M., Bögels, S. M., Speckens, A. E. M., Dammers, J. T., Wolfers, T., Buitelaar, J. K., \& Greven, C. U. (2021). A randomised controlled trial (MindChamp) of a mindfulness-based intervention for children with ADHD and their parents. Journal of Child Psychology and Psychiatry and Allied Disciplines. https:// doi.org/10.1111/jcpp.13430.
Simonoff, E., Pickles, A., Charman, T., Chandler, S., Loucas, T., \& Baird, G. (2008). Psychiatric disorders in children with autism spectrum disorders: Prevalence, comorbidity, and associated factors in a population-derived sample. Journal of the American Academy of Child and Adolescent Psychiatry, 47(8), 921-929. https://doi.org/10.1097/CHI.0b013e318179964f.

Soke, G. N., Maenner, M. J., Christensen, D., Kurzius-Spencer, M., \& Schieve, L. A. (2018). Prevalence of co-occurring medical and behavioral conditions/symptoms among 4- and 8-year-old children with autism spectrum disorder in selected areas of the United States in 2010. Journal of Autism and Developmental Disorders, 48(8), 2663-2676. https://doi.org/10.1007/s10803-018-3521-1.

Sonuga-Barke, E. J., Brandeis, D., Cortese, S., Daley, D., Ferrin, M., Holtmann, M., Stevenson, J., Danckaerts, M., van der Oord, S., Döpfner, M., Dittmann, D. W., Simonoff, E., Zuddas, A., Banaschewski, T., Buitelaar, J., Coghill, D., Hollis, C., Konofal, D., Lecendreux, M., \& ...European Guidelines ADHD-group. (2013). Nonpharmacological interventions for ADHD: Systematic review and meta-analyses of randomized controlled trials of dietary and psychological treatments. American Journal of Psychiatry, 170(3), 275-289. https://doi.org/10.1176/appi.ajp.2012. 12070991.

Tarver, J., Daley, D., \& Sayal, K. (2014). Attention-deficit hyperactivity disorder (ADHD): An updated review of the essential facts. Child: Care, Health and Development, 40(6), 762-774. https://doi.org/ 10.1111/cch.12139.

Tarver, J., Daley, D., \& Sayal, K. (2015). Beyond symptom control for attention-deficit hyperactivity disorder (ADHD): What can parents do to improve outcomes? Child: Care. Health and Development, 41(1), 1-14. https://doi.org/10.1111/cch.12159.

Thapar, A., Harrington, R., Ross, K., \& McGuffin, P. (2000). Does the definition of ADHD affect heritability? Journal of the American Academy of Child and Adolescent Psychiatry, 39(12), 1528-1536. https://doi.org/10.1097/00004583-200012000-00015.

Thapar, A., Cooper, M., \& Rutter, M. (2017). Neurodevelopmental disorders. Lancet. Psychiatry, 4(4), 339-346. https://doi.org/10. 1016/s2215-0366(16)30376-5.

Tick, B., Bolton, P., Happe, F., Rutter, M., \& Rijsdijk, F. (2016a). Heritability of autism spectrum disorders: A meta-analysis of twin studies. Journal of Child Psychology and Psychiatry and Allied Disciplines, 57(5), 585-595. https://doi.org/10.1111/jcpp.12499.

Tick, B., Colvert, E., McEwen, F., Stewart, C., Woodhouse, E., Gillan, N., Hallett, V., Lietz, S., Garnett, T., Simonoff, E., Ronald, A., Bolton, P., Happé, F., \& Rijsdijk, F. (2016b). Autism spectrum disorders and other mental health problems: Exploring etiological overlaps and phenotypic causal associations. Journal of the American Academy of Child and Adolescent Psychiatry, 55(2), 106-113.e104. https://doi.org/10.1016/j.jaac.2015.11.013.

Trillingsgaard, T., Trillingsgaard, A., \& Webster-Stratton, C. (2014). Assessing the effectiveness of the 'Incredible Years((R)) parent training' to parents of young children with ADHD symptoms - A preliminary report. Scandinavian Journal of Psychology, 55(6), 538-545. https://doi.org/10.1111/sjop.12155.

van Steijn, D. J., Oerlemans, A. M., van Aken, M. A., Buitelaar, J. K., \& Rommelse, N. N. (2014). The reciprocal relationship of ASD, ADHD, depressive symptoms, and stress in parents of children with ASD and/or ADHD. Journal of Autism and Developmental Disorders, 44(5), 1064-1076. https://doi.org/10.1007/ s10803-013-1958-9.

Wachtel, K., \& Carter, A. S. (2008). Reaction to diagnosis and parenting styles among mothers of young children with ASDs. Autism: The International Journal of Research \& Practice, 12(5), 575-594. 
Weingarten, K. (2016). The art of reflection: Turning the strange into the familiar. Family Process, 55(2), 195-210. https://doi.org/10. 1111/famp.12158.

World Medical Association Declaration of Helsinki: Ethical principles for medical research involving human subjects. (2013).
JAMA, 310(20), 2191-2194. https://doi.org/10.1001/jama.2013. 281053.

Publisher's Note Springer Nature remains neutral with regard to jurisdictional claims in published maps and institutional affiliations. 